thorium-beryllium system to cover some aspects of burn-up and reactivity, but the full development of work on practical reactor behaviour must await better computing facilities.

Greater awareness in Australia of the potential of radioisotope applications is reported, and an increase is forecast in their uses in all fields, covering a wide range of techniques. However, in Australia radioisotope methods are still being used to a lesser extent than in other industrialized countries. Eighteen investigations were undertaken for outside organizations. In ten of these, radioisotopes produced in Hifar were used. Extensive assistance was given to the Hunter Valley Research Foundation in a study of silt movement in Newcastle Harbour. Other effluent tracer investigations were carried out for industrial organizations in New South Wales and Tasmania. A service was set up for labelling organic compounds with radioactive hydrogon (tritium). The long-term production of cobalt- 60 for teletherapy use continued. At June 30, 1961, cobalt being irradiated had reached an estimated activity of 22,500 curies, of which approximately 80 per cent was at a sufficient strength for teletherapy use.

The main project of tho small physics research group is the development, in conjunction with the Radiophysics Division of the Commonwealth Scientific and Industrial Research Organization, of a technique using radioisotopes to trace fine particulate matter in the atmosphere-namely, what happens to silver iodide when released at the base of a cloud. The Technical Physics Section evolved techniques for making solid-state $\alpha$-particle detectors, using semi- conductor materials, and research is being conducted into their performance and proporties. Shortage of staff and laboratory space prevented much expansion of biological research; but some investigations have been made. In the section of the annual report dealing with health and safety it is reported that the quantity and variety of radioactive and toxic material stored and handled at the Research Establishment increased greatly during the year. Nevertheless, no person received a significant exposure to radiation or beryllium.

The Australian Institute of Nuclear Science and Engineering, with its headquarters at Lucas Heights, is an organization established jointly by the Commission and the Australian universities, and a portion of the annual report is devoted to its activities. The Establishment collaborated closely with the Institute in more than thirty projects, details of which are given in the report. An Institute Fellow was appointed to work at the Research Establishment on improving existing methods and developing new methods of using radioactive techniques in geological age determinations. The Commission awarded a number of undergraduate scholarships each year during 1954-57 as part of its plan to overcome a shortago of graduates in geology, geophysics, metallurgy and chemical engineering. A total of 28 students was awarded scholarships; the majority have since graduated and ten students were still undergoing training during 1960. Fifty-four separate research contracts have been awarded by the Commission to universities and hospitals in Australia, of a total valuo of $£ 269,000$.

S. WEINTROUB

\title{
UNIVERSITY ORGANIZATION IN INDIA
}

$\mathrm{T}$ HE Proceedings of the Third Conference of the Vice-Chancellors of Indian Universities*, convened by the University Grants Commission and the Ministry of Education at New Delhi during October 28-29, 1961, include a notable inaugural address by Dr. K. L. Shrimali, Minister of Education, which indicates a striking contrast in the attitude of the Indian Government to universitios compared with that of the South African Government. Dr. Shrimali was deeply concerned over recent events in Aligarh Muslim University and was fully aware that they represented a major failure of education, but it was for the universities themselves to correct this prejudico, intoloranco and bigotry. They were not concerned solely with the training of minds but also with the education of emotions, cultivation of good taste and sense of deceney and the development of character. Dr. Shrimali thought that the tutorial system could provide the answer to most problems, but, as free corporations, universities had the authority to make what changes they considered necessary to discharge their responsibilities to society, and a high sense of responsibility on the part of the universities was the essential condition for the preservation of their autonomy. Dr. Shrimali recognized that both Government and universities were liable to orr, and it was their duty to correct each other, but the only way in a free society was to reach agreement through discussion.

* Government of India. University Grants Commission and Ministry of Education. Proceedings of the Vice-Chancellors' Conference, 1961. Pp. $\nabla+58$. (New Delhi: University Grants Commission and Ministry of Education, 1902.)
The whole temper of Dr. Shrimali's address was in line with Sir Eric Ashby's recent Chancellor's Lecture to the University of the Witwatersrand, and he urged that, more than money, to improve the quality of education are needed dodicated teachers who would stimulate thinking among the students, give them a vision of true greatness and inspire faith to dedicate themselves to the realization of groat ideals.

The Proceedings also incorporate the address of Dr. D. S. Kothari, chairman of the University Grants Commission, on education and the universities, discussing the expansion of Indian universities. In this Dr. Kothari deals with the acute problem of student wastage and measures to reduce this and some proposals of the report on goneral education. such as refresher courses and seminars for a selected number of college and university teachers, the ostablishment of centres of advanced study on an all-India basis and promotion of academic mobility (for which purpose the universities must be bilingual, using English and the regional language). Establishment of about 12 new universities is envisaged during the Third Five Year Plan, issued in June 1961, to provide the anticipated additional 100,000 places required to koep pace with the expansion of the population. The Proceedings also include the recommendations of the Committee on Standards of Education, tho Committee on Instruments of Education (dealing with entrance qualifications and tests for admission, training of teachers, quality and availability of university text-books, common calondar of terms, examination dates and 
publication of results and uniformity of standards) and the Committee on 'Emotional Integration', which considered the preparation of text-books, the role of student unions and the resolution of religious conflicts. It was recommended that all universities which make available a certain minimum number of places for students from other parts of India and those bearing denominational names should discard the denominational component of their title. The Committee on Standards of Education recommended an increase in the number of technical schools, polytechnies, trade schools, etc., and improvement of the student-teacher ratio to at least $1: 7$ or $1: 10$. English was considered the only appropriate medium of instruction in postgraduate education at present, and the Committee recommended that the University Grants Commission should play a more active part in the development of all higher education. Research centres should be built up around outstanding personalities.

\section{THE CHALLENGE OF HUNGER}

$\mathrm{T}$ HE greatest challenge that faces mankind to-day and in the coming decades is the problem of feeding the growing population of the world. While the world population is increasing at an unprecedented rate, food production in the areas of the world where most people do not have enough to eat is lagging. Thus, to-day, mankind as a whole is not being adequately fed, and there is a population increase of such dimensions that by the end of this century-possibly earlier-the number of mouths to be fed will be more than double.

For several years the Food and Agriculture Organization of the United Nations has pointed out the dangers inherent in this situation. It has stressed that food production as a whole, but especially in the underdeveloped and developing countries, is not increasing fast enough. The rate of populationgrowth in the developing countries is more than 2 per cent, while the volume of agricultural production is increasing at slightly less than 3 per cent per annum -a margin that is clearly precarious. Any major set-back in agriculture in any part of the world, owing to climatic or other natural factors, could quickly wipe out the gains which have been so painfully won.

Statisties set out by Dr. Binai Ranjan. Sen, the director-general of the Food and Agriculture Organization, reveal the realism of this warning. Estimates of world agricultural production in 1960-61 (excluding mainland China) show an increase of no more than 1 per cent over production in the previous seasonwhich is less than the estimated rate of population growth of 1.6 per cent. If mainland China is included in the world agricultural production figures, the total production of 1960-61 would probably be less than that of 1959-60 instead of a 1 per cent increase. Set-backs due to bad weather in several regions of the world indicate that the $1961-62$ production may again be small.

Since the Second World War there has been a great expansion in the production of food and agricultural products, but by far the largest part of this has taken place in Europe, in North America and Oceania. All theso are countries where standards of living are high and the people are well fed and adequately nourished. In the food-deficient regions of Africa, Asia and Latin America, the increases have so far barely kept pace with the population increase. Thus, although the Far East Region, which is the worst nourished and most populous area in the world, has had a good harvest for three successive years and, excluding mainland China, the 1960-61 food production per head has only brought consumption levels up to those of 1939.

In other words, improvements in diets which could have been expected as a result of increases in food. production have, in fact, been largely nullified by population increase. In Latin America, for example, per capita food production continues to lag behind pre-war levels. In the Near East, however, per capita production is now about 10 per cent greater than the low levels prevailing in the pre-war period. In Africa, a rather stationary situation prevailed with some ups and downs. These regional figures reveal wide differences among individual countries.

A statistical survey of the incidence of hunger and malnutrition was recently made by Dr. P. V. Sukhatme, director of the Statistics Division of the Food and Agriculture Organization, based on the international reference scale for calorie requirements and on the variation in energy expenditure among men of the reference age group. Applying the Food and Agriculture Organization calorie standards as a basis of comparison for the quantitative aspects of the diet, the study showed that calorie supplies in Europe, North America and Oceania are of the order of more than 3,100 calories per capita per day and exceed the requirements by about 20 per cent. In the Near East, Africa and Latin America, they are about equal to the requirements, amounting to some 2,400 . In the Far East, the supplies are of the order of only 2,050 compared with a calorie requirement of some 2,300 . The supply thus falls short of the requirement by 11 per cent.

This gap is particularly striking when compared with the total calorie supplies of other regions. Thus, the shortage in the Far East is of a quantity large enough to feed the entire population of the Near East. Even for other regions where the overall picture looks balanced, there are wide variations within the region. In the Near East, for example, there is apparently enough food in a group of countries where one-half of the population lives: the other half lives in a relatively poorer area. The calorie supplies of this area are only $2,100-2,200$ per capita per day. It is therefore justifiable to conclude that many millions of people in the world still go hungry at least for a part of their lives.

Thus, the recent study conducted by the Food and Agriculture Organization* has shown that the gap of 11 per cent between the calorie supplies and the calorie requirements in the Far East is shared by one-fifth to one-fourth of the population of the region. Since this region comprises half the total world population, it is clear that a conservative estimate of the proportion of undernourished in the world is between 10 and 15 per cent. In actual numbers this means that between 300 and 500 million go hungry for part of their lives, even in normal times.

* UNESCO Courier, July-August (1962). 